\title{
NILAI RELIGIOSITAS DALAM KUMPULAN CERPEN KARYA HABIBURRAHMAN EL-SHIRAZY
}

\author{
RELIGIOSITY VALUE IN A COLLECTION OF SHORT STORIES \\ BY HABIBURRAHMAN EL-SHIRAZY
}

\author{
Tara Aulia; Maria L.A.S; Noor Cahaya \\ Program Studi Pendidikan Bahasa Indonesia \\ FKIP Universitas Lambung Mangkurat \\ taraaulia.ta39@gmail.com
}

\begin{abstract}
Abstrak
Penelitian ini bertujuan untuk mendeskripsikan nilai religiositas dalam kumpulan cerpen karya Habiburrahman El-Shirazy. Nilai religiositas yang terkandung dalam kumpulan cerpen tersebut dapat digunakan sebagai bahan alternatif dalam pembelajaran sastra di sekolah. Pendekatan penelitian yang digunakan, yaitu deskriptif kualitatif. Sumber datanya berupa kumpulan cerpen karya Habiburrahman El-Shirazy. Hasil penelitian dari nilai religiositas dalam kumpulan cerpen ini ialah akidah yang meliputi 1) iman kepada Allah Swt, 2) iman kepada kitab Allah Swt, 3) iman kenada rasul Allah Swt., dan 4) iman kepada qada dan qadar. Syariah yang meliputi 1) taaruf, 2) pinangan, 3) pernikahan, dan 4) wudu. Akhlak yang meliputi 1) akhlak pribadi, 2) akhlak dalam keluarga, dan 3) akhlak dalam bergaul.

Kata Kunci: nilai, religiositas, cerpen.
\end{abstract}

\section{Abstract}

The purpose of the study is to describe the religiosity value of a collection by Habiburrahman El-Shirazy. The religiosity value collection contained in the short stories could be use as an alternative material to literature study at school. The approach of the study is qualitative descriptive. The data sources are the collection of short stories by Habiburrahman El-Shirazy. The results of the study religiosity value in the collection of the short stories are faith which covers 1) faith in Allah Swt., 2) faith in holy book's of Allah Swt., 3) faith in prophet's Allah Swt., 4) faith in Qada and Qadar. A sharia which covers 1) taaruf, 2) proposal, 3) marriage, and 4) ablution. Morals which covers 1) personal morals, 2) child in the family, and 3) morals in association.

Keywords: value, religiosity, short stories.

\section{Pendahuluan}

Nilai-nilai yang baik selalu terkandung dalam karya sastra yang baik pula, nilai tersebut dapat secara tersirat maupun tersurat. Dialog antartokoh yang terdapat dalam karya sasrtra dapat menyinggung langsung tentang suatu nilai dalam kehidupan atau sebaliknya. Unsur religius dan keagamaan dapat dihadirkan dalam sastra. Religius adalah konsep keagamaan yang menyebabkan manusia bertingkah laku sesuai dengan perintah Tuhannya, sedangkan keagamaan adalah sistem yang mengatur keyakinan manusia kepada Tuhannya. Berbeda halnya dengan sastra yang memengaruhi sikap dan perilaku para pembacanya. Nilai religiositas dibahas, melihat dari segi di mana kurangnya nilai reli-giositas yang dimiliki oleh anak-anak 
sekarang. Maraknya kasus pergaulan bebas, obat-obatan hingga pelecehan seksual sampai pem-bunuhan, disebabkan karena kurangnya pemahaman agama serta lemahnya iman yang dimiliki seseorang. Dengan mempelajari nilai religiositas yang

Sastra tidak hanya sebagai hiburan untuk pembacanya, melain-kan juga memberikan pemahaman tentang nilai religius yang paparkan melalui cerita kehidupan dan nilai-nilai kehidupan di dalamnya. Karya sastra biasanya juga mengandung nilai-nilai kehidupan dari suatu kelompok masyarakat. Nilai tersebut digambarkan pengarang lewat gambaran watak para tokohnya maupun setting/latar ceritanya. Nilai-nilai tersebut berpengaruh secara individual pada masing-masing tokohnya, terlihat dalam bentuk-bentuk perubahan sikap, perubahan kepribadian,

\section{Metode Penelitian}

Metode penelitian yang digunakan, yaitu deskriptif. Penelitian deskriptif bertujuan untuk menjabarkan atau memaparkan keadaan di lapangan secara

\section{Jenis Penelitian}

Penelitian ini menggunakan pendekatan kualitatif. Pendekatan kualitatif yaitu dalam penelitiannya baik secara keseluruhan. me-manfaatkan caracara penafsiran dengan menampilkannya dalam bentuk pemaparan atau deskripsi. terdapat dalam kumpulan cerpen karya Habiburrahman El-Shirazy, diharapkan siswa mampu membuat dirinya lebih peka lagi terhadap hubungan manusia dengan pencipta-Nya, dan hubungan manusia dengan sesama manusia.

pola hidup, perilaku, dan pandangan hidup (Harmaningrini, 2017:15-22).

Rumusan masalah yang akan dipaparkan dalam penelitian ini ialah, bagaimanakah nilai religiositas yang terkandung dalam kumpulan cerpen karya Habiburrahman El-Shirazy. Penelitian ini ber-tujuan untuk mendeskripsikan nilai religiositas dalam kumpulan cerpen karya Habiburrahman El-Shirazy. Nilai religiositas yang terdapat dalam kum-pulan cerpen tersebut dapat digunakan sebagai bahan alternatif dalam pem-belajaran sastra di sekolah.

berurutan dengan fakta-fakta dan pengertian yang tepat, selain itu juga membuat data-data saling berhubungan satu sama lain, serta dengan tujuan mencari pemahaman observasi.

Pada penelitian ini, peneliti mendeskripsikan nilai religiositas yang terkandung dalam kumpulan cerpen karya Habiburrahman El-Shirazy.

\section{Data dan Teknik Pengumpulan Data}

Data pada penelitian ini, yaitu unsur ekstrinsik cerpen, berupa kata atau 
kalimat yang mengandung nilai religiositas dalam kumpulan cerpen karya Habiburrahman El-Shirazy. Sumber data pada penelitian ini, yaitu kumpulan cerpen karya Habiburrahman El-Shirazy diantaranya, (1) Pudarnya Pesona Cleopatra, (2) Nyanyian Cinta, (3) Ketika Cinta Berbuah Surga, (4) Seratus Peluru untuk Amru.

Penelitian ini menggunakan teknik studi pustaka, yaitu teknik pemerolehan data melalui sumber tertulis, seperti buku bacaan umum, buku bacaan alamiah, naskah, surat kabar, dan puisi. Peneliti menggunakan teknik studi pustaka dengan membaca dan mengidentifikasi kumpulan cerpen karya Habiburrahman El-Shirazy sebagai sumber data, kemudian peneliti membuat catatan mengenai hal-hal yang dirasa penting yang termasuk dalam sumber data dan sesuai dengan hal yang akan diteliti oleh penulis.

Langkah-langkah yang dilakukan peneliti untuk mengumpulkan data sebagai berikut:

a. Membaca keseluruhan cerpen yang diteliti secara berulang-ulang untuk memahami isinya secara menyeluruh.

\section{Hasil Penelitian dan Pembahasan}

Nilai religiositas yang terdapat dalam kumpulan cerpen karya b. Mencatat bagian-bagian yang dirasa penting, seperti kata-kata atau kalimat yang berkaitan dengan rumusan masalah yang akan peneliti lakukan.

c. Menandai dan mengklasifikasikan data yang menggambarkan nilai religiositas dalam kumpulan cerpen karya Habiburrahman El-Shirazy.

\section{Teknik Analisis Data}

Teknik analisis data adalah langkah untuk men-cari dan menyusun data se-cara berurutan. Langkah-langkah yang dilakukan peneliti untuk menganalisis data sebagai berikut:

a. Menjabarkan kembali data yang telah dideskripsikan yang sebelumnya telah diklasifikasikan, kemudian ditafsirkan dan disusun secara berurutan.

b. Membuat ringkasan inti cerita dari keseluruhan isi cerpen yangditeliti, sehingga isi cerpen dapat dipahami secara mendalam.

c. Membuat simpulan mengenai nilainilai religiositas yang terkandung dalam cerpen yang diteliti.

Habiburrahman El-Shirazy ini meliputi 1) Akidah, 2) Syariah, dan 3) Akhlak. 


\section{Akidah}

Akidah adalah keimanan atau kepercayaan. Akidah merupakan masalah menyeluruh dalam Islam. Akidah menjadi landasan utama keyakinan seorang muslim. Sebaliknya, seseorang yang mampu menegakkan perilaku yang mencerminkan nilai islami dalam hidup dan dalam ke-hidupannya, orang itulah

\section{a. Iman kepada Allah Swt.}

Pada cerpen "Pudarnya Pesona Cleopatra" iman kepada Allah Swt. terlihat pada kutipan:

"Mas, bangun. Sudah jam setengah empat. Mas belum salat Isya." Kata Raihana membangunkanku. Aku terbangun dengan perasaan kecewa. "Maafkan aku Mas, membuat Mas kurang suka, tetapi Mas belum salat Isya."

\section{b. Iman kepada Kitab Allah Swt.}

Cerpen "Ketika Cinta Berbuah Surga" menceritakan kisah se-orang raja yang senang sekali mengajarkan anaknya membaca Alquran. Terlihat bahwa sang raja ingin anaknya menjadi anak yang beriman, dalam hal ini mengimani kitab Allah Swt., yaitu Alquran terdapat pada kutipan:
"Saat-saat paling menyenangkan bagi sang raja adalah ketika dia mengajari anaknya itu membaca

\section{c. Iman kepada Rasul Allah Swt.}

yang dapat menerangkan bahwa ia memiliki akidah atau menunjukkan kualitas iman yang dimiliki oleh orang tersebut. Kumpulan cerpen karya Habiburrahman El-Shirazy ini mengandung beberapa rukun iman, di antaranya a. iman kepada Allah Swt., b. iman kepada kitab Allah Swt., c. iman kepada rasul Allah Swt., dan d. iman kepada qada dan qadar.

(Pudarnya Pesona Cleopatra, hlm.3).

Kutipan di atas terlihat Raihana yang membangunkan suaminya untuk segera mengerjakan salat. Salat ialah menghadapkan jiwa dan raganya kepada Zat Yang Maha Agung Allah Swt, yang dilakukan oleh hamba yang beriman.

\section{Alquran." (Ketika Cinta Berbuah Surga, hlm.1).}

Sebuah keutamaan bagi orang tua untuk mengajarkan Alquran kepada anaknya. Sebab, orang tua adalah madrasah pertama bagi seorang anak. Allah Swt., menjamin keberkahan di akhirat kelak bagi orang tua yang anaknya membaca dan mengamalkan Alquran.

Iman kepada rasul Allah Swt. dalam cerpen "Nyanyian Cinta" terlihat ketika 
Prof. Dr. Abdul Aziz Abduh, Guru Besar Ilmu Dakwah menjelaskan perihal amanah, yaitu salah satu sifat utama yang dimiliki oleh Rasulullah Saw. Hal ini terlihat pada kutipan:

"Sebelum diangkat menjadi seorang nabi, Muhammad Saw telah dikenal sebagai orang yang paling menjaga

Kutipan tersebut menunjukkan adanya penjelasan dari Prof. Dr. Abdul Aziz kepada mahasiswanya mengenai satu dari empat sifat utama rasul. Penjelasan yang disampaikan oleh tokoh tersebut menandakan bahwa ia percaya akan sifatsifat yang ada dalam diri Rasulullah Saw. Oleh sebab itu, ia menyampaikannya kembali kepada para mahasiswanya agar mereka tahu dan juga mempercayai adanya rasul Allah Swt.

\section{d. Iman kepada Qada dan Qadar}

Iman kepada. qada dan qadar terdapat dalam cerpen "Nyanyian Cinta", terlihat pada kutipan:

"Ia bergerak. Beberapa orang bergerak. Pak kepala desa, dua polisi dan Mahmud mengikuti. Mahmud hanya pasrah kepada Allah Swt." (Nyanyian Cinta, hlm 15).

Kutipan di atas menunjukkan bahwa tokoh Mahmud sedang pasrah atau berserah diri kepada Allah Swt. Ia mengimani qada dan qadar dan mempercayai takdir yang terjadi amanah di seantereo Kota Makkah. Sehingga, beliau diberi gelar Al-Amin. Orang yang sangat bisa dipercaya, orang yang sangat menjaga amanah. Sifat inilah yang semestinya dimiliki setiap muslim," jelas guru Abdul Aziz. (Nyanyian Cinta, hlm.1).

kepadanya. Keseimbangan jiwa akan didapat jika seseorang percayaan kepada takdir, tidak cepat ber-putus asa karena suatu kegagalan dan tidak pula menjadi berbangga diri karena suatu keberuntungan. Sebab, semua persoalan berasal dari Allah SWT., sudah sepatutnya sebagai manusia mengembalikan segala persoalan kepada Allah Yang Mahakuasa pula.

\section{Syariah}

Syariah adalah hukum Allah Swt., dan perundang-undangan yang datangnya dari Allah Swt., Tuhan Yang Maha sempurna.

\section{a. Taaruf}

Cerpen "Nyayian Cinta" yang memuat perihal taaruf terlihat ketika Mahmud bersedia menerima tawaran untuk dinikahkan dengan seorang gadis pilihan kepala desa. Sebelum pernikahan dilakukan, Mahmud terlebih dahulu melakukan taaruf atau proses perkenalan 
dengan gadis tersebut. Hal ini terlihat pada kutipan:

"Minggu berikutnya diadakan acara taaruf antara Mahmud dengan cucu Pak Ragib itu, acara dihadiri kepala desa. Mahmud hanya bisa menunduk dengan hati dan jantung berdebar-debar." (Nyanyian Cinta, hlm.18).

\section{b. Pinangan}

Dalam cerpen "Pudarnya Pesona Cleopatra", pinangan terjadi ketika adanya tokoh Aku yang akan melakukan khitbah kepada Raihana atas perjodohan yang dilakukan oleh ibunya dengan ibu Raihana. Hal ini terlihat pada kutipan:

"Saat khitbah (lamaran)
sekilas kutatap wajah
Raihana. Benar kata Aida,
adikku. Ia memang baby face
dan anggun." (Pudarnya
Pesona Cleopatra, hlm.1).

Kutipan di atas menunjukkan dilaksanakannya acara khitbah antara tokoh Aku dengan Raihana. Tokoh Aku terlihat sedang menatap wajah Raihana ketika acara khitbah berlangsung.

\section{c. Pernikahan}

Pernikahan ditunjukkan dalam cerpen "Nyanyian Cinta". Hal ini terlihat saat dilangsungkannya akad nikah oleh Mahmud dan Hafshah. Pernikahan yang dilakukan di musim semi membuat langit terlihat lebih cerah. Hal ini termuat dalam kutipan:

"Musim semi yang penuh barakah. Pagi yang indah.
Langit yang cerah. Orangorang menatap hari dengan penuh gairah. Begitu juga Hafshah dan Mahmud. Pagi hari Jumat itu berlangsung akad nikah di desa bersuka cita. Anak-anak mendendangkan lagu kebahagiaan dan cinta." (Nyanyian Cinta, hlm.19).

\section{d. Wudu}

Perihal wudu terdapat dalam cerpen "Ketika Cinta Berbuah Surga" yang terlihat dalam kutipan:

"Anak itu mengambil air wudu, lalu salat dua rakaat." (Ketika Cinta Berbuah Surga, hlm.3).

Kutipan tersebut menunjukkan bahwa tokoh tersebut menyucikan dirinya dengan air terlebih dahulu sebelum melaksanakan salat dua rakaat.

\section{Akhlak}

Akhlak merupakan perilaku yang ditunjukkan oleh manusia yang ditimbulkan dari lubuk hatinya yang paling dalam.

\section{a. Akhlak Pribadi}

Cerpen "Pudarnya Pesona

Cleopatra" yang menunjukkan adanya akhlak terhadap diri sendiri terdapat pada kutipan:

“... hatiku menangisi kebohonganku dan kepurapuraanku." (Pudarnya Pesona Cleopatra, hlm.2). 
Akhlak pribadi yang terdapat dalam kutipan tersebut merupakan wujud dari tokoh Aku yang membohongi dirinya sendiri untuk terus berpura-pura mencintai Raihana.

\section{b. Akhlak dalam Keluaga}

Akhlak dalam keluarga merupakan cara seseorang berperilaku di lingkungan keluarganya.

\section{1) Akhlak Anak kepada Ibu}

Dalam hal ini, terlihat pada cerpen "Pudarnya Pesona Cleopatra" yang menunjukkan bakti kepada ibu. Bakti kepada ibu juga termasuk akhlak dalam keluarga, tentang bagaimana cara kita bersikap atau berakhlak kepada orang tua. Hal tersebut ditunjukkan dalam kutipan:

$$
\begin{aligned}
& \text { “... dalam pergulatan jiwa } \\
& \text { yang sulit berhari-hari, } \\
& \text { akhirnya aku. Aku pasrah. }
\end{aligned}
$$

Aku menuruti keinginan

ibu. Aku tak mau mengecewakan ibu. Aku ingin menjadi mentari pagi dihatinya, meskipun untuk itu aku harus mengorbankan diriku." (Pudarnya Pesona Cleopatra, hlm.1).

\section{2) Akhlak Anak kepada Ayah}

\section{Cerpen "Ketika Cinta Berbuah} Surga" menunjukkan adanya akhlak anak kepada ayah. Menceritakan bagaimana seorang anak bernama Said bersikap sopan dan patuh kepada ayahnya. Hal ini terlihat dalam kutipan:

"Akhirnya, Said meminta izin kepada ayahnya untuk pergi mencari teman sejati." (Ketika

Cinta Berbuah Surga, hlm.3).

\section{3) Akhlak Istri kepada Suami}

Dalam cerpen "Pudarnya Pesona Cleopatra", terlihat adanya akhlak istri kepada suami yang ditunjukkan oleh tokoh Raihana untuk mengabdi kepada suaminya, terlihat pada kutipan:

"Kumohon bukalah sedikit hatimu untuk menjadi ruang bagi pengabdianku, bagi penyempurnaan ibadahku di dunia ini," Raihana mengiba penuh pasrah. (Pudarnya Pesona Cleopatra, hlm.2).

Tokoh Raihana ingin menunjukkan baktinya kepada suaminya dengan harapan agar ibadahnya lebih baik di dunia.

\section{4) Akhlak Cucu kepada Kakek}

Akhlak baik yang ditunjukkan Amru kepada kakeknya terlihat dalam kutipan:

"Kek, Amru pamit dulu ngambil air ya," Amru mencium tangan kakeknya yang berdiri di pintu gubuk. (Seratus Peluru untuk Amru, hlm.2).

Cara amru berpamitan dan mencium tangan kakeknya merupakan akhlak yang menunjukkan rasa sayang dam hormatnya kepada sang kakek.

\section{c. Akhlak dalam Bergaul}

Kutipan yang menunjukkan akhlak dalam bergaul pada cerpen "Ketika Cinta Berbuah Surga" juga terlihat pada: 
“... tidak ayal lagi, Said menangis terharu, lalu Said memeluk anak pencari kayu bakar itu erat-erat seraya berkata, engkau teman sejatiku! Engkau teman sejatiku! Engkau temanku masuk surga!" Kata Said. (Ketika Cinta Berbuah Surga, hlm.5).

Said begitu senang mendapat teman baik yang selama ini ia cari. Said menunjukkan cara bergaulnya dengan memeluk temannya dan mengatakan mereka adalah teman masuk surga. Hal yang dilakukan Said merupakan salah satu bukti wujud akhlak dalam bergaul.

\section{Simpulan dan Saran}

\section{Simpulan}

Berdasarkan hasil analisis dari kumpulan cerpen karya Habiburrahman El-Shirazy dapat diambil simpulan, nilai religiositas yang terkandung di dalam masing-masing cerpennya berupa 1) nilai akidah yang meliputi (1) Iman kepada Allah, (2)Iman kepada Kitab Allah, (3) Iman kepada Rasul Allah, dan 4) Iman kepada Qada dan Qadar. 2) Nilai syariah meliputi (1) Taaruf, (2) Pinangan, (3) Pernikahan, dan (4) Wudu. 3) Nilai akhlak yang meliputi (1) Akhlak Pribadi, (2) Akhlak dalam keluarga, mencakup akhlak anak kepada ibu, akhlak anak kepada ayah, akhlak cucu kepada kakek, akhlak istri kepada suami, dan (3) Akhlak dalam Bergaul.

\section{Saran}

Saran yang diberikan penulis setelah melakukan penelitian ini yaitu, pendidik dan orang tua, atau semua orang yang berkomitmen pada perkembangan dunia pendidikan, dapat menjadikan kumpulan cerpen karya Habiburrahman El-Shirazy sebagai alternatif materi bahan ajar dalam pendidikan yang memberikan kebebasan kepada peserta didiknya untuk menelaah kajian isi, pesan, dan kandungan cerpen.

\section{Daftar Pustaka}

Atmosuwito, Subijantoro. 2010. Perihal Sastra Religiusitas dalam Sastra. Bandung: Sinar Baru Algensindo.

Aviyah, Evi dan Muhammad Farid. (2014). Religiusitas, Kontrol Diri, dan Kenakalan Remaja. Jurnal Psikologi Indonesia, vol. 3, no. 2. Mei 2014.

Azizah, Nur. (2015). Perilaku Moral dan Religiusitas Siswa Berlatar Belakang Pendidikan Umum dan Agama. Jurnal Psikologi, vol. 33, no. 2. Februari 2015.

Daradjat, Zakiah, dkk. (1984). Dasardasar Agama Islam. Jakarta: Karya Unipress.

Dewi, Yusra. (2012). Nilai-nilai Pendidikan Religus Dalam Dongeng Dalam Buku Teks Bahasa Indonesia Sekolah Menengah Pertama Kelas VII Terbitan Pusat Perbukuan Departemen Pendidikan Nasional. Jurnal Pena, vol, 2, no. 2. Juli 2012.

Endaswara, Suwardi. (2013). Sosiologi Sastra, Studi, Teori, dan Interpretasi. Yogyakarta: Penerbit Ombak. 
Harmaningrini, Etty. (2017). Aspek Religius dalam Novel Anak Teladan Karya A. Rahman Rahim dan Implementasinya Pada Pembelajaran Sastra di Sekolah Dasar (Suatu Pendekatan Semiotik). Jurnal Stilistika, vol. 3, no. 2. Agustus 2017.

Ihsan, Fuad. (2013). Dasar-Dasar Kependidikan. Jakarta: Rineka Cipta. Jabrohim. (1994). Pengajaran Sastra. Yogyakarta : Pustaka Pelajar.

Laelasari, Paris, dan Ahmadi F. (2018). Analisis Unsur Intrinsik dan Nilai Pendidikan Karakter Dalam Cerpen "Kisah Tiga Kerajaan Lampau" Karya David Victor. Jurnal Pendidikan Bahasa dan Sastra Indonesia, vol. 1, no. 3. Mei 2018.

Mangunwijaya. (1982). Sastra Dan Religiositas. Jakarta: Sinar Harapan.
Nurhayati, Siti. (2014). Ensiklopedia Tata Bahasa Indonesia. Jakarta: Kunci Aksara.

Ramadani, Munaris, dan Suyanto. (2018). Nilai-nilai Sosial dalam Kumpulan Cerpen Berhala Karya Danarto dan Rancangannya di SMA. Jurnal Kata (Bahasa, Sastra, dan Pembelajarannya). Januari 2018.

Ratna, Nyoman Kutha. (2011). Teori, Metode, dan Teknik Penelitian Sastra. Yogyakarta: Pustaka Pelajar.

Razak, Nazaruddin. (1973). Dienul Islam. Bandung: PT. Alma'arif.

Rifa'i, Muh. Khoirul. (2016). Internalisasi Nilai-Nilai Religius Berbasis Multikultural Dalam Membentuk Insan Kamil. Jurnal Pendidikan Agama Islam, vol. 4, no. 1. Mei 2016. 